\title{
Using a Microsoft Surface Pro 3 tablet for mathematics support
}

\author{
Michael Cross, Academic Skills Advice, University of Bradford, m.a.cross@bradford.ac.uk
}

\section{Abstract}

This paper reviews the benefits of using a Microsoft Surface Pro tablet in a mathematics support setting. The context of its use is foregrounded and associated educational issues explored.

Keywords: Microsoft Surface Pro, tablet, skills support, independent learner, technologyenhanced learning.

\section{A brief overview of the situation}

Over the last 9 years, at the University of Bradford, the maths advisers (the author and his colleague, Helen Jackson) have not found technology, specifically laptops, netbooks, iPads or smart pens (e.g. Livescribe), to be very useful in helping with the face to face mathematics support, which is the core of the service. However, this year two Microsoft Surface Pro 3 tablets have been introduced, primarily for use in maths clinics (drop-ins).

To give some background and context, the mathematics and statistics skills development support at the University of Bradford is part of the University's Academic Skills Advice service, which is not affiliated with any specific faculty. The service is available for all and it seeks to be part of a system that encourages students "to seek guidance when they require it" (Thomas, 2002, p.439). Furthermore, the aim is to provide support which acknowledges that any student is studying within a specific discipline and they are the owners of their own skills development and the advisers are agents who can support them. If this is not established then students may well avoid the service because they will see it as "lacking relevance to their course" (Durking \& Main, 2002, p.26) or worse, it may be teaching "context-independent techniques" (Wingate, 2007, p.394) which do not "help students to assimilate into the practices of their discipline" (Wingate, 2007, p.394).

For the mathematics support, it would be fairly typical for a student's first point of contact with an adviser to be in a maths clinic, which is a drop-in session where both advisers are usually present. Students from any discipline are welcome to the maths clinics which usually run three times a week. The clinics run out of general teaching rooms which the advisers have to book and advertised in advance. There is no permanent base. In addition, at other times, students are supported via a range of traditional and electronic resources as well as bookable appointments; all of which are well used. There is telephone and email advice available, but demand is low.

\section{A wider context}

Over the last three years, approximately, the entire service has undergone small but significant changes. The focus has been to try and maintain a welcoming 'can do' approach to students while also emphasising high quality practice and recognising that students "have to become independent learners, taking responsibility for their own learning" (Wingate, 2007, p.394). The ideal approach is to assume that all students are already taking responsibility and are developing independence and then to create environments and processes that support this assumption. This could be seen as focusing on the highest common denominator and emphasising the positives rather than the negatives. During this process, the team were introduced to the concept of heutagogy (Jones, 2014) via the CETL- MSOR 2014 conference in Cardiff. It seemed to fit well with the approach the team were already articulating and their reaction was similar to that of a conference delegate, who felt they could "[k]eep developing my heutagogy methodology now it has a name" (sigma Network, 
2014). Broadly speaking heutagogy "may be viewed as a natural progression from earlier educational methodologies" (Hase \& Kenyon, 2000). It is seeking to move on from pedagogic and androgogic approaches by incorporating self-directed learning and, beyond that, to have at its core the concept of "truly self-determined learning" (Hase \& Kenyon, 2000).

To this end, one of the small changes trialled by the senior skills adviser (Russell Delderfield) was an increase in the use of screens - specifically the introduction of a projector with smart pen and also a large touch screen. Students were informed that any written work they brought with them needed to be in electronic form and it would then be viewed on a screen together with an adviser. There were, already, clear guidelines about working with live drafts in place but viewing student's work on a screen appeared to emphasise the distance between the adviser and the work itself in a way that had been hard to achieve with some students. The advisers had found that explaining how they work to the students had not always translated into understanding. Regardless of what was said to them, it had seemed for some students that handing a piece of paper over to the adviser led to an abdication of responsibility, as if some of their independence had been surrendered.

Very quickly, after starting the trial, the advisers noted a significant improvement. They found that students were getting the message without it needing to be articulated repeatedly. One explanation for this phenomenon is that viewing an electronic copy of something feels less tangible and therefore one gives it less weight or significance. Possibly because it allows one to be removed from it and to consider it differently. Another is that the electronic version can feel like a copy of the 'real' thing. There is evidence that "screen-based reading behaviour is characterized by more time on browsing and scanning, keyword spotting, one-time reading, non-linear reading, and more reading selectively; while less time is spent on in-depth reading and concentrated reading, and sustained attention is decreasing" (Liu, 2005, p.705) and that as a result, one engages with electronic text more superficially. This can be a good thing when the aim is to keep the emphasis on the learner who is the focus of the development and away from any individual piece of work. Whatever the reason, it was hoped that similar improvements could be achieved in the mathematics support setting too.

\section{Patient zero - the case for a tablet}

In 2014/15 an engineering student who regularly attended maths clinics demonstrated his sophisticated use of a Microsoft Surface Pro tablet (Windows 8) over a number of months. He made good use of the document retrieval and management features (past papers, formula sheets, tutorial notes) and he performed all of his working out and took all of his notes using the Surface pen (stylus) and the software, Microsoft OneNote. Each week he would revisit lecture 'handouts' and annotate electronic copies with the pen and, overall, his utilisation of this device seemed markedly different to other students' laptop and tablet usage. The lightweight nature, the speedy switching between documents and the ability to write smoothly, directly onto the tablet were all striking features. There even appeared to be some rudimentary maths-writing recognition features. Further research found similar stories online (Ong, 2015). It seemed to be a useful device to support personal learning and it seemed worthwhile to explore its potential in a mathematics support setting.

Ahern-Dodson \& Comer's (2013) research into academic writing on a tablet provides further support. They start by wondering, themselves, whether "a pad of paper could arguably achieve some of the same ends" (p.67). However, they proceed to identify some features of tablets, specifically, that resulted in participants favouring them over the use of paper. For them it was primarily down to the flexibility offered. But they also raise the issue of "visibility" (p.68). In their case it is the visibility of writing notes that is under scrutiny but in the maths clinics it would be the visibility of the learning resources (of which there are a great many) particularly the ones 
developed 'in house'. It would be interesting to see if they were more visible to the students, and therefore more accessible, via tablets than in physical folders. For comparison a photograph of the original paper resource folders is given in Figure 1, together with a screen-shot of the electronic resources as they are currently displayed on the tablets.

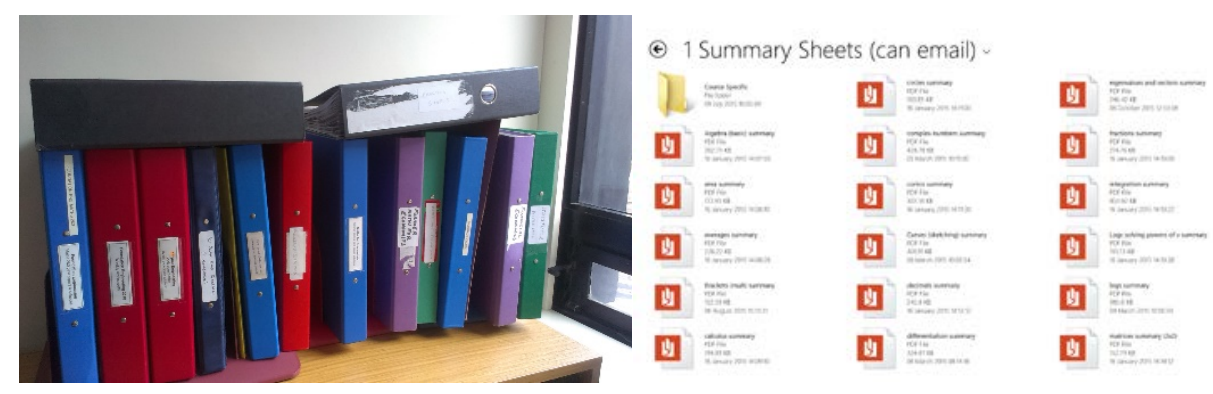

Figure 1. Paper based and electronic resources - before and after.

It is also pertinent that Ahern-Dodson \& Comer (2013) concluded that the tablet was not just another computer. They found that it was something unique and they recommended that educators pay "deliberate attention to the tablet as a unique technology" (p.75). In their specific case it was distinctive because it had limitations that could have a negative effect on writing practice. However their advice, to consider it as something different within an educational context, seems sound. Furthermore they emphasise that the introduction of technology is not a neutral activity and what it does "to us and for us" (p.75) needs to be critically considered.

In addition to making the resources more visible, the University of Bradford has a strong environmental commitment but the mathematics support has traditionally used a lot of paper. It was hoped that the introduction of tablets would help to reduce paper consumption. On a very practical level it would also mean not having to transport overflowing folders, full of resources, on small trolleys to destinations far and wide on campus only to find the folder required was the one left behind.

\section{Specific mathematics support issues}

As part of the service improvements outlined earlier, underpinned by heutagogic principles, the frequency of the general maths clinics was increased to three times per week and disciplinespecific clinics were removed from the schedule in 2014/15. Again it was intended to help raise the perceptions of students to the highest common denominator because it was noted that some students took more responsibility in clinics, when they saw how other students engaged with the process, than they did in appointments. In addition, over time, the subject specific clinics had unfortunately become identified with remedial support. Straight away it was clear that it had brought about improvements to the service. There was a reduction in the number of appointments booked and the attendance at the clinics noticeably increased. Historically, students who struggle with independence are relatively small in number but can be very hard to help. Often they are struggling to transition to higher education having been "spoon-fed" (National Audit Office, 2002, p.15) prior to coming to university. Focusing on the general clinic environment that communicates the need for independence without the need to keep verbalising it (and thereby drawing attention to it as a deficit) turned out to be a much more positive experience and it served everyone better.

One notable exception which typically occurs in the run-up to examinations is the demand for standard solutions to past papers. Although small in number, there are students who behave as though solutions are the most important aspect of their revision process. It is not an exaggeration to state that some students become almost obsessed with past paper solutions but are not generally receptive to advice that involves more sophisticated exam-preparation and other ways of 
revising. Typically it is the same students who report back after the exams, disappointed with their grade and declaring the paper to be unreasonably hard. It was this behaviour, in particular, that led to the consideration of changing the medium by which the materials were accessed and viewed (from paper to electronic). The hope was that it would have a similar effect to the changes reported by the advisers responsible for writing skills and study skills support.

\section{The way forward: buying and setting up the tablets}

Two Microsoft Surface Pro 3 tablets (i3 64GB) were purchased (summer 2015). Styluses (Surface Pen) are included in the price but Type Covers (keyboards) were also purchased. Microsoft offer a $10 \%$ educational discount. In the context of the maths clinics, the specific expectations and objectives were:

- To increase access to all resources;

- To reduce quantity of resources being transported;

- To do hand-written maths 'on screen';

- To provide option to easily copy, mark-up and distribute (email) varied materials;

- To cut down on amount of paper being used in accordance with University's Green Commitment;

- To have the convenience of a full-powered and configurable laptop without the bulk/inconvenience.

During August and September, 2015, having purchased the devices, one of the advisers took responsibility for upgrading to Windows 10 and configuring the tablets and the other took responsibility for scanning as many hand-written notes as possible and generally organising the electronic documentation. Many of papers were dog-eared and were written on the very thin squared paper so they had to be hand-scanned otherwise they ripped or jammed in the scanner. Both of these roles were more time consuming than anticipated. A shared Microsoft account was created which gave access to a Microsoft Cloud service which, in turn, automated the synchronisation of documents between both machines.

\section{Practical benefits}

The good news is that the tablets have been useful and would be missed if they were no longer available. They have not been obtrusive, and, curiously, many of their most useful features are quite mundane. The amount of materials being transported to each clinic has dramatically reduced and this is very helpful. It also really helps that Windows 10 actually starts and wakes very quickly and that the screen is bright and very clear. The fact the tablets are lightweight and compact has been of particular benefit. It is no trouble to carry them around or physically pass them to a student. Also, they have a built-in, adjustable kickstand so they can sit on a cluttered desk very easily (see Figure 2).

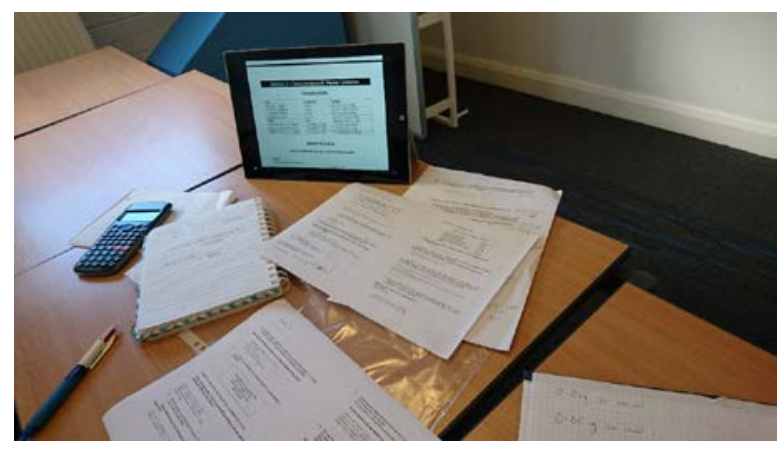

Figure 2. The tablet in a maths support clinic. 
Reflecting on the use of tablets after the first semester (approximately 40 clinics held, averaging 23 hours each) it was felt they had been a success and the positives, in clinics, have been:

- increased access to the resources;

- perceived increase in student autonomy by both advisers;

- sense of increased efficiency in clinics;

- good for organising documents;

- used a lot to look at documents;

- easier access to the Virtual Learning Environment (VLE), websites and online graphing and these have all been done more than expected;

- fairly regularly emailing of documents to students, and the emailing does not take so long as to be prohibitive;

- booking follow up appointments via online diary system;

- a small footprint - lightweight, compact and stands easily on table - this has been a very valuable aspect of its ease of use.

These positive outcomes are despite the fact that there was quite a significant overhead in setting the tablets up. Many technical issues had to be overcome which did require technical experience and confidence. There are too many issues to list them all but it is worth noting that the keyboards are required even though they are sold separately and the 'Ink to Math' feature does not seem good enough, yet, to replace Equation Editor or Math Type (see Figure 3). It was surprising how little the unique feature of being able to write smoothly on the screen has been utilised in clinics although it has proved useful for taking notes in meetings and is still being explored for its potential with regard to screen capture and email advice.

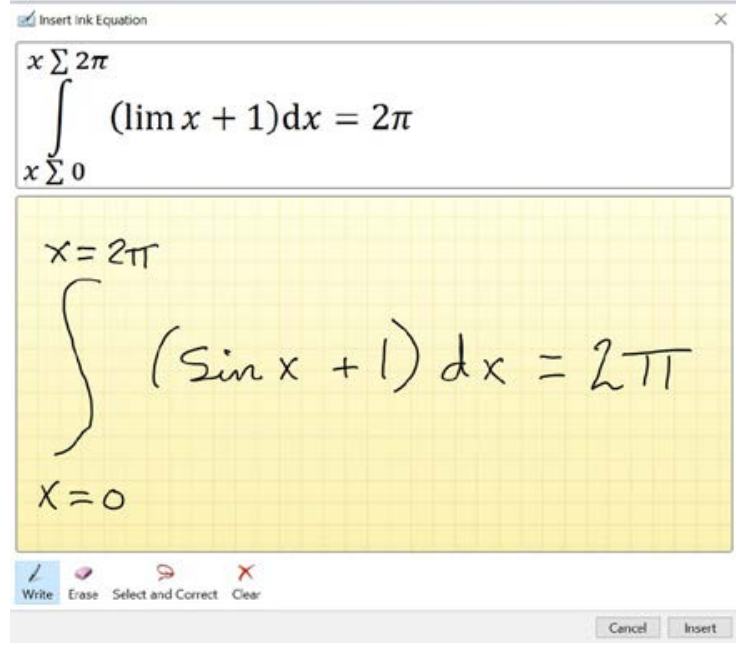

Figure 3. Microsoft Ink to Math feature.

\section{Heutagogic Benefits}

Returning to the idea of heutagogy, it was found that the tablets did support the ethos of increasing independence (raising to the highest common denominator). Whether for reasons already identified, or for reasons unknown, there was a clear improvement. For example, students focused less intensely upon the solutions to past papers in electronic form than they did in paper form. In previous years some students had tried to photograph the papers while they thought they were not being observed but there was not any commensurate behaviour with the electronic versions this year. Although copies cannot be taken, students are encouraged to compare their solutions to the standard solutions if it seems that it will help them in their development and students seemed to 
engage with this process very sensibly. Students also demonstrated awareness of the need to share the tablets with their fellow attendees. This seemed to lead to an organic process whereby students shared resources, including the tablets, with each other and group work and cooperation between students occurred in a mutually beneficial and socially appealing way.

Typically the model of support, within a clinic, is that advisers engage with a student and then move on to another, sometimes leaving the tablet with them. Each tablet almost represents the adviser in their absence and crucially interacting with the resources on the tablet seems to require more independence from the students. However it does not labour the message and thus, it manages the relationship boundaries more effectively than having the adviser actually point out to a student that they need to be more independent and do something for themselves. Crucially, with some students, it enables them to actively work on something, particularly when they arrive unprepared. For example they may be asked to log into their VLE or be given access to an appropriate resource. Previously it was easy to get bogged down in an interaction where a student just could not perform any independent work whatsoever. The adviser could become tied to them in the clinic setting and somehow this reinforced their helplessness. Although not necessarily "immobilised by an expectation of failure" (Hoyne \& McNaught, 2013, p.110) students can exhibit levels of passivity in their education which is very close to this and they need help breaking out of it. The use of the tablets has helped with this and subsequently allowed for the advisers' time to be shared among everyone more equitably.

\section{Summary}

The introduction of the Microsoft Surface Pro 3 has been beneficial to the students and the staff, it had had clear practical benefits simply stemming from it being compact and lightweight and able to stand alone. The technology and operating system are fairly new which led to significant configuration and optimisation overheads but did not out-weigh the benefits. It was surprising that the features of the pen, which seem to make it a boon as a personal learning tool, were not well used in the clinic setting. Some of its benefits seem to be borne from the interaction between what it offers, how it is used and the context within which it is used and these have generally been educational benefits which gently reinforce the heutagogic approach.

\section{References}

Ahern-Dodson, J. and Comer, D.K., 2014. Multidisciplinarity and the tablet: A study of writing practices. The WAC Journal, 24, pp.63-82. Available at:

http://wac.colostate.edu/journal/vol24/ahern-dodson.pdf [Accessed 29 February 2016].

Hase, S. and Kenyon, C., 2000. From andragogy to heutagogy. Ultibase Articles, 5(3), pp.1-10. Available at: http://pandora.nla.gov.au/nph-

wb/20010220130000/http://ultibase.rmit.edu.au/Articles/dec00/hase2.htm [Accessed 4 April 2016].

Hoyne, G. and McNaught, K., 2013. Understanding the psychology of seeking support to increase Health Science student engagement in academic support services. A Practice Report. The International Journal of the First Year in Higher Education, 4(1), pp.109-116. Available at: https://fyhejournal.com/article/view/149 [Accessed 29 February 2016].

Jones, C., 2014. Beyond pedagogy content knowledge: retrofitting heutagogy to mathematics [Online Abstract]. Keynote CETL-MSOR Conference 2014. Available at: http://www.sigmanetwork.ac.uk/wp-content/uploads/2014/09/ColinJones_Abstract.pdf [Accessed 28 February 2016].

Liu, Z., 2005. Reading behaviour in the digital environment: Changes in reading behaviour over the past ten years. Journal of Documentation, 61(6), pp.700-712. Available at: http://works.bepress.com/ziming_liu/8/ [Accessed 20 February 2016]. 
National Audit Office, 2002. Improving Student Achievement in English Higher Education. Report by the Comptroller and Auditor General, HC 486. London: The Stationery Office. Available at: https://www.nao.org.uk/wp-content/uploads/2002/01/0102486es.pdf [Accessed 29 February 2016].

Ong, S., 2015. Ultimate Student Guide to Using Microsoft Surface 3 and Surface Pro 3 [Video]. Available at: https://www.youtube.com/watch?v=aEb573aGQpA [Accessed 20 February 2016].

sigma Network, 2014. CETL-MSOR Conference 2014 [Online]. Available at: http://www.sigmanetwork.ac.uk/cetl-msor/cetl-msor-conference-2014 [Accessed 28 February 2016].

Thomas, L., 2002. Student retention in higher education: the role of institutional habitus. Journal of Education Policy, 17(4), pp.423-442. Available at:

http://www.tandfonline.com/doi/abs/10.1080/02680930210140257 [Accessed 29 February 2016]

Wingate, U., 2007. A Framework for Transition: Supporting 'Learning to Learn' in Higher Education. Higher Education Quarterly, 61(3), pp.391-405. Available at:

http://onlinelibrary.wiley.com/doi/10.1111/j.1468-2273.2007.00361.x/abstract [Accessed 29

February 2016]. 